\title{
MANAGEMENT OF PREGNANCY IN A UNIVERSITY HOSPITAL: A 6-YEAR STUDY
}

Tânia Regina Schupp, Seizo Miyadahira, Soubhi Kahhale and Marcelo Zugaib

RHCFAP/3016

SCHUPP TR et al. - Management of pregnancy in a University Hospital: a 6-year study. Rev. Hosp. Clín. Fac. Med. S. Paulo 55(4):137-144, 2000.

In order to evaluate the obstetric care in the Obstetric Clinic of the Gynaecology and Obstetrics Department of University of São Paulo, the authors present a survey of the management of pregnancy during the 6-year period from 1993 to 1998.

The number of deliveries increased during the study by $45 \%$ over the 6 years. During this same period the number of fetal deaths was $526(4.48 \%)$, but there was a significant decrease $(\mathrm{p}<0.05)$ in the incidence of fetal death. However, there was no concomitant increase in the proportion of pregnant women with prenatal care that could explain this improvement. Incidence of premature labor also decreased considerably.

The authors believe that the increment in the number of deliveries was due mainly to the increasing number of pregnant women referred to our service. The efforts made by the service towards decreasing the time of hospitalization of both newborns in the nursery and the mothers in the hospital made this possible.

Despite the increasing number of deliveries, there was a significant improvement in the management of pregnancy during the period of study. This improvement may be a consequence of the standardization of a protocol of management of pregnancy based on the recent progress in scientific and technological knowledge.

DESCRIPTORS: Pregnancy. Universities. Management.

Management and outcome of pregnancy may vary substantially depending on the type of hospital (urban or rural, tertiary or primary, private or public or university hospital), incidence of associated maternal and fetal diseases, and the socioeconomic situation of the country.

Although recent progress in prenatal care has been enormous, continuous improvements in maternal and fetal health care are needed. Among these improvements to better insure positive pregnancy outcomes is the expansion of the quality of care to socially and economically deprived patients. Unfortunately, these are the majority in our institution.

Stillbirths tend to decline as the quality of care during and throughout pregnancy improves. With improvements in prenatal care and proper hospitalization some of these deaths are preventable.

With the aim of analyzing the impact of this recent progress, the authors present an audit of the management and outcome of pregnancy in our service.

\section{MATERIAL AND METHODS}

This retrospective study was conducted at the Obstetrics and

From the Department of Obstetrics and Gynaecology, Hospital das Clínicas, Faculty of Medicine, University of São Paulo.
Gynaecology Department of the University of São Paulo School of Medicine, Brazil during the 6 years from January 1, 1993 through December 31, 1998. All patients were from the Hospital das Clínicas, which is a university hospital and a tertiary hospital; the majority of these patients were from the most socially and economically deprived segment of our population. Maternal charts of all deliveries were retrospectively reviewed in order to analyze maternal age, fetal sex, type of delivery, type of presentation, presence of prenatal care, incidence of multiple pregnancy, occurrence of premature labor, incidence of fetal death, and frequency of low and very low birth weight. During this time, 11442 pregnant women came to our service for 
obstetric care with a total of 11733 deliveries.

Adolescent pregnancy was defined as maternal age equal to or less than 19 years, whereas elderly pregnancy was defined as maternal age 35 years and over. Premature labor was defined as labor before the $37^{\text {th }}$ week of gestation according to the World Health Organization, and postdate pregnancy was defined as labor beyond the $42^{\text {nd }}$ week of pregnancy. We defined fetal death as the delivery of any deceased conceptus weighing more than $500 \mathrm{~g}$. Low birth weight was defined as weight lower than $2500 \mathrm{~g}$, very low birth weight was defined as weight under $1500 \mathrm{~g}$, and extremely low birth weight was defined as a weight less than 1000 g. Fetal macrosomia was defined as a birth weight of more than $4000 \mathrm{~g}$.

Infants were classified as small for gestational age, defined as birth weight below the tenth percentile, or big for gestational age, defined as birth weight above the ninetieth percentile. These percentiles were based on the data from Ramos ${ }^{1}$. The percentile values were calculated from the data from our service, and they are applicable in the city of São Paulo.

Numbers were expressed as mean \pm \pm SD. Categorical data were compared with chi-square test, and continuous data were compared with Student $t$ test. $\mathrm{P}<0.05$ was considered statistically significant.

\section{RESULTS}

The number of deliveries increased during the years of this study. In 1993 the total number of deliveries was 1650 . In the last year, the total number of the deliveries was 2396 . This represents an increase of $45 \%$ in 6 years (Fig. 1). There were 2983 women (25.6\%) who did not receive any kind of obstetric care or evaluation during gestation until delivery. During the study, there was no significant changes in this parameter (Fig. 2). There were 5982 male infants and 5697 female infants. Fifty four infants were of indefinite sex.

During this study the number of fetal deaths was 526 (4.48\%). There was a significant decrease in the incidence of fetal death during this 6-year period (Fig. 3).

\section{MATERNAL AGE}

The mean age of pregnant women in this study was $27.01 \pm \pm 6.7$ years. The youngest woman was 10 years old and the oldest 57 years old. There were 1610 pregnancies among adolescent mothers or $13.9 \%$ of the total. On the other hand, 1722 women were 35 years

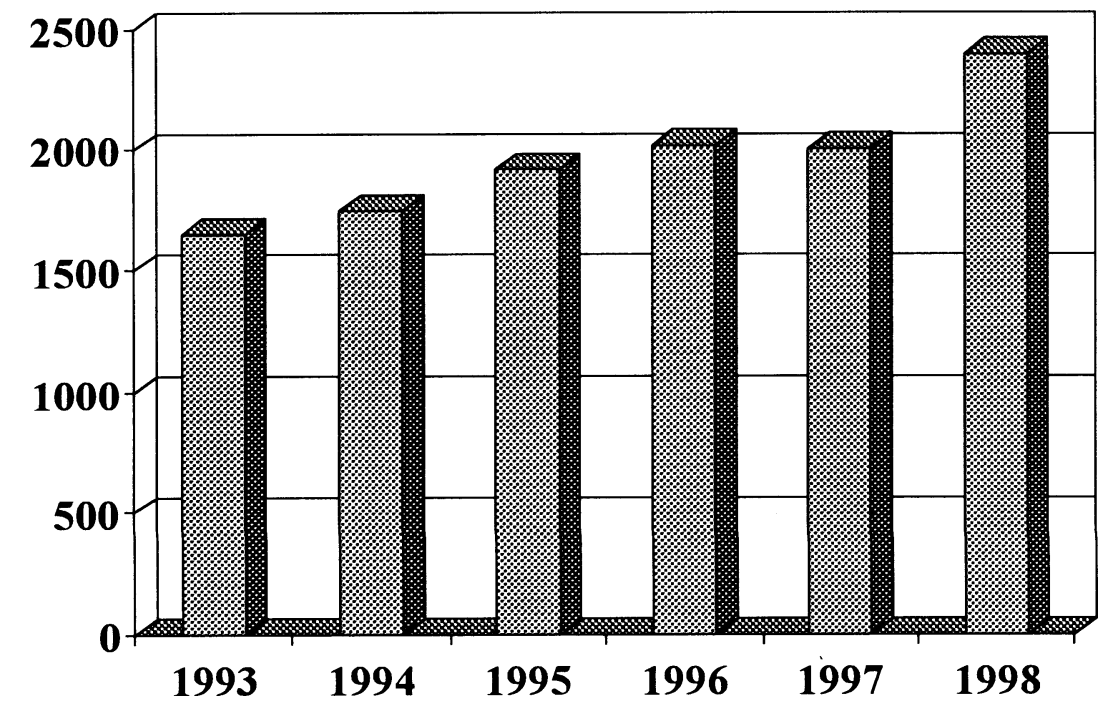

Figure 1 - Evolution of numbers of deliveries through the study.

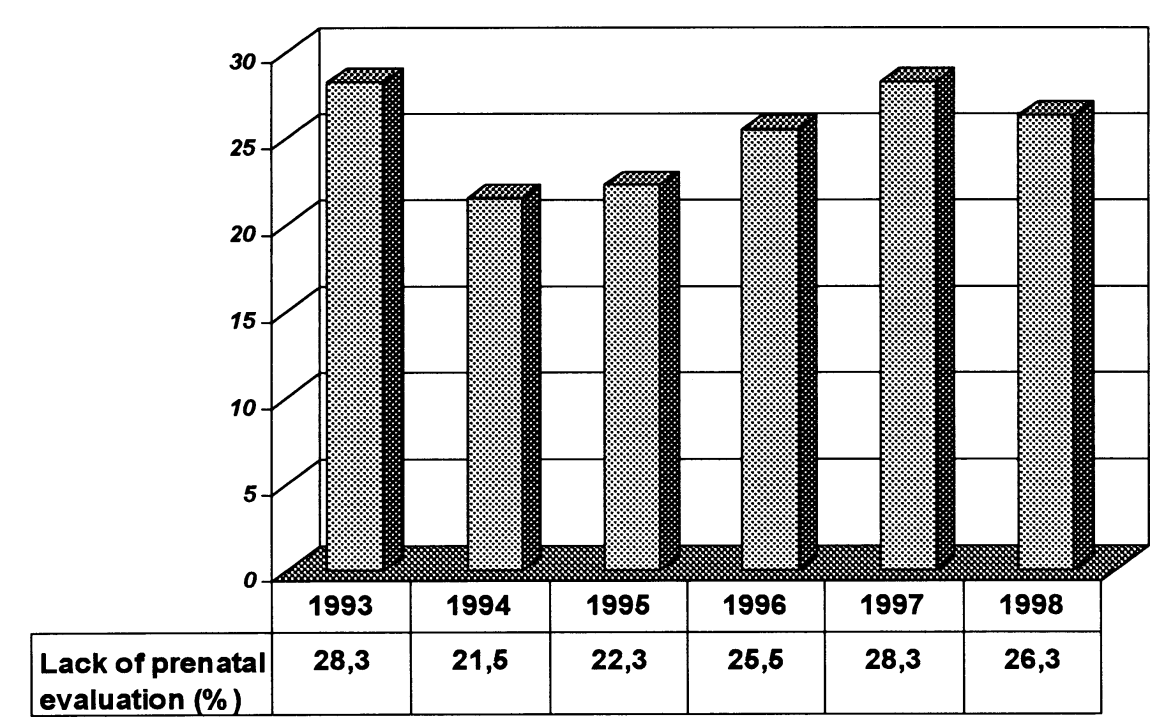

Figure 2 - Proportion of pregnant women without prenatal evaluation during the years study. There was no significant $(\mathrm{p}>0.05)$ difference between the proportion through the years. 
old and over (14.8\%). Of these, 467 or $4 \%$ were 40 years old and over.

Adolescent mothers presented the highest rate $(33.7 \%)$ of non-assisted pregnancies, which was significantly higher $(\mathrm{p}<0.05)$ than the rate for the 20-34 year-old group (25.4\%). The incidence of non-assisted pregnancy was $17.9 \%$ among the 35 year-old and over group, and it was $14.9 \%$ for the 40 year-old and over group. These incidences were significantly lower than that for the 20-34 year-old group ( $\mathrm{p}<$ $0.05)$.

The frequency of fetal death was $5.5 \%$ among adolescent mothers and $4.1 \%$ among mothers 35 years old and over. There were no statistical differences between the incidences of fetal death among elderly mothers when compared to the group of pregnant women between 20 and 34 years old. However, the rate of fetal death among adolescent mothers was significantly higher ( $\mathrm{p}<0.0001)$ when compared to the group of pregnant women between 20 and 34 years old (3.2\%).

\section{GESTATIONAL AGE}

The mean gestational age was 37.3 \pm \pm 4.9 weeks. Premature labor was present in 3275 pregnant women, representing $28.1 \%$ of the total deliveries. The incidence of premature labor was $29.6 \%$ in 1993 and $26.2 \%$ in 1998 , representing a significant drop in the incidence of premature labor during this study ( $\mathrm{p}<0.02$ ).

Postdate pregnancy was present in 116 women, representing $1.0 \%$ of all deliveries. There were no significant changes in the incidence of postdate pregnancy. The proportion of deliveries according to the gestational age is shown in figure 4.

\section{MULTIFETAL PREGNANCY}

There were 274 multifetal pregnancies $(2.4 \%)$ and 11168 singleton preg-

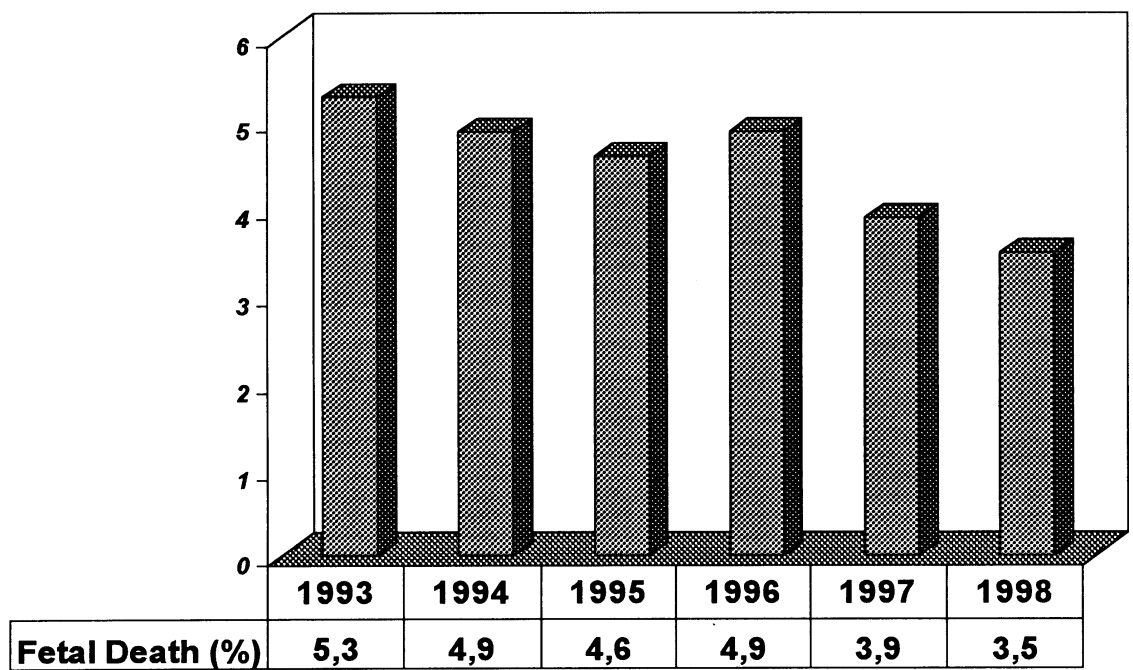

Figure 3 - Fetal death rate during the study. Note that there was a significant $(p<0.05)$ drop in the fetal death rate.

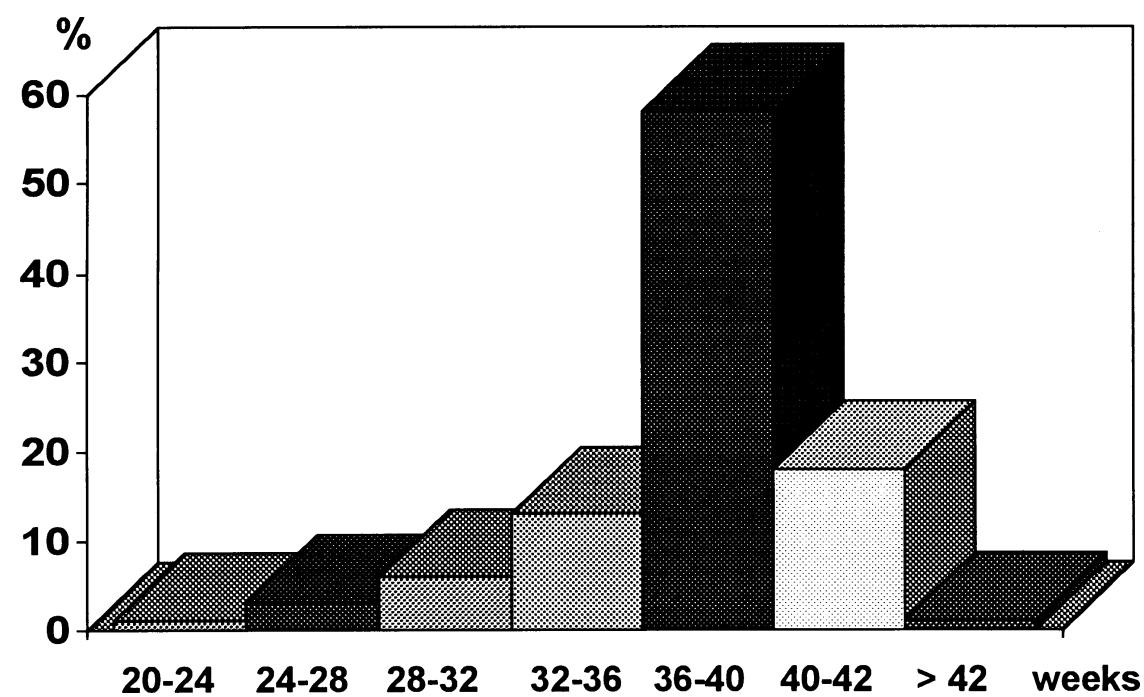

Figure 4 - Proportion of deliveries according to the gestational age.

nancies $(97.6 \%)$. From these multifetal pregnancies, there were 258 twins, 15 triplets and 1 set of quadruplets. As shown in the table 1 , the average duration of gestation and the average birth weight decreased dramatically as the number of fetuses increased.

As shown in the table 2, the average maternal age increased with the number of fetuses. No differences in sex ratio were observed.

There were 40 fetal deaths among multifetal pregnancies. This incidence was significantly higher than in singleton pregnancies The distribution of fetal death is shown in table 3 .

\section{BIRTH WEIGHT}

While 8228 fetuses presented normal weight (2500 to $4000 \mathrm{~g}$ ) at birth, 2130 fetuses presented weight between 1500 and $2500 \mathrm{~g}$ (low birth weight), 534 fetuses presented weight between 1000 and $1500 \mathrm{~g}$ (very low birth 
weight), and 401 fetuses presented weight under $1000 \mathrm{~g}$ (extremely low birth weight). 361 fetuses were macrosomic. There were no available data in 79 charts. The corresponding average gestational age of each group of fetuses is shown in table 4. There was no statistical difference in birth weights between adolescent mothers, elderly mothers, and mothers between 20 and 34 years old.

Table 5 summarizes the correlation between birth weight and gestational age, dividing infants into 3 groupsnormal, small, and big for gestational age as defined according to the percentile curves.

\section{TYPE OF DELIVERY}

The total proportion of cesarean sections was $53.8 \%$, while $46.8 \%$ of deliveries were vaginal, with or without instrumentation. The proportion of cesarean sections increased during the study, but this difference was not significant ( $p>0.05)$. Meanwhile, the proportion of vaginal deliveries without forceps increased significantly $(\mathrm{p}<$ $0.01)$ and the proportion of forceps deliveries decreased significantly ( $\mathrm{p}<$ 0.01) (Table 6 and Fig. 5).

As shown in the table 7, the proportion of cesarean sections increased as the number of fetuses increased.

In the majority of pregnancies, the type of presentation was cephalic $(91.2 \%)$. The proportion of pelvic presentations was $8.5 \%$, and only $0.3 \%$ had a transverse presentation (Table 8 ).

\section{DISCUSSION}

The present study showed a notable increase in the number of deliveries in our institution over the 6-year study period. This increment in the number of deliveries was mainly due to the increasing number of pregnant women referred to our service. The efforts
Table 1 - Average length of gestation and birth weight for pregnancies with known time of ovulation and 20 or more weeks gestation.

\begin{tabular}{lccc}
\hline No. of fetuses & No. of pregnancies & Weeks of gestation** & Birth weight $(\mathbf{g}) * *^{* *}{ }^{*}$ \\
\hline Singleton & $11,063^{*}$ & $37.7 \pm \pm 3.5$ & $2868 \pm \pm 771$ \\
Twins & 258 & $35.3 \pm \pm 3.9$ & $2176 \pm \pm 680$ \\
Triplets & 15 & $34.2 \pm \pm 2.6$ & $1864 \pm \pm 508$ \\
Quadruplets & 1 & 31 & $1203 \pm \pm 88$ \\
\hline
\end{tabular}

* - In 105 pregnant women with singleton pregnancy, the time of ovulation was not known or it was less than 20 weeks.

$* *-\mathrm{p}<0.01$

Table 2 - Average maternal age and sex ratio for pregnancies with known time of ovulation and 20 or more weeks gestation.

\begin{tabular}{lccc}
\hline No. of fetuses & No. of pregnancies & Sex ratio M:F & Maternal age \\
\hline Singleton & $11,063^{*}$ & $1.05: 1$ & $26.9 \pm \pm 6.7$ \\
Twins & 258 & $1: 1$ & $28.4 \pm \pm 6.4$ \\
Triplets & 15 & $1.37: 1$ & $28.9 \pm \pm 6.0$ \\
Quadruplets & 1 & $0: 1$ & 17 \\
\hline
\end{tabular}

* - In 105 pregnant women with singleton pregnancy, the time of ovulation was not known or it was less than 20 weeks.

Table 3 - Distribution of fetal death in multifetal pregnancy.

\begin{tabular}{lccc}
\hline No. of fetuses & No. of pregnancies & Fetal deaths & Death of pair of twins \\
\hline Twins & 258 & 36 & 9 \\
Triplets & 15 & 4 & $1 *$ \\
Quadruplets & 1 & 0 & 0 \\
\hline
\end{tabular}

* - Death of two out of a triplet

Table 4 - Average length of gestation according to the birth weight.

\begin{tabular}{lccc}
\hline Birth weight & No. of pregnancies & \% & Weeks of gestation \\
\hline Macrosomic & 361 & 3.1 & $39.6 \pm \pm 3.3$ \\
Normal & 8228 & 70.1 & $38.7 \pm \pm 3.8$ \\
Low birth weight & 2130 & 18.1 & $35.1 \pm \pm 4.6$ \\
Very low birth weight & 534 & 4.6 & $30.8 \pm \pm 3.6$ \\
Extremely low birth weight & 401 & 3.4 & $26.9 \pm \pm 4.3$ \\
Unknown & 79 & 0.7 & \\
\hline Total & $\mathbf{1 1 , 7 3 3}$ & $\mathbf{1 0 0}$ & \\
\hline
\end{tabular}

Table 5 - Distribution of deliveries according to birth weight and gestational age.

\begin{tabular}{lcc}
\hline Birth weight & No. of pregnancies & \% \\
\hline Small for gestational age & 1414 & 12.3 \\
Big for gestational age & 966 & 8.4 \\
Normal & 9153 & 79.3 \\
Total & $\mathbf{1 1 , 5 3 3} *$ & $\mathbf{1 0 0}$
\end{tabular}

* - In 200 pregnant women, the time of gestation was not known or it was less than 20 weeks or the birth weight was not known. 
made by the service towards decreasing the time of hospitalization of both newborn in the nursery, and the mother in the hospital made this possible.

Despite the lack of amelioration in the proportion of prenatal assistance, there was a significant decrease in the proportion of fetal deaths. This reduction was probably a consequence of the standardization of a protocol of management of pregnancy based on the recent progress in scientific and technological knowledge ${ }^{2}$. In 1996, according to official data ${ }^{3}, 14.3 \%$ of pregnant women in Brazil did not receive any kind of prenatal assistance. This proportion is less than that found in our study group (25.6\%).

The authors observed a high rate of adolescent mothers. This is a very common finding in developing countries, but it is not an exclusive figure from these countries. Despite prevention efforts at the state and federal levels, adolescent pregnancy rates in the United States are among the highest in the developed countries ${ }^{4}$. In Brazil, adolescent pregnancy is about $22 \%$ of all deliveries ${ }^{5,6}$.

The high proportion of adolescent mothers was correlated with a lower incidence of prenatal assistance. However, this difference did not account for higher incidence of fetal deaths in this group of women. On the other hand, elderly mothers presented a higher proportion of prenatal assistance when compared to the mothers in the 20-34 year-old group, but a lower incidence of fetal death was not found.

In a prospective and comparative study performed in the Netherlands, Smit et al. ${ }^{7}$ did not find any difference between elderly and younger pregnant women, except for a lower average birth weight for the elderly group, probably related to a higher rate of cesarean section in this group ${ }^{8}$. Similarly, Anate and Akeredolu in another comparative study also found a significantly ( $p<0.001)$ higher rate of cesar-

Table 6 - Type of delivery during 6-year study.

\begin{tabular}{cccccccc}
\hline $\begin{array}{c}\text { Year of } \\
\text { study }\end{array}$ & Total & $\begin{array}{c}\text { Cesarean } \\
\text { Section }\end{array}$ & $\%$ & $\begin{array}{c}\text { Vaginal } \\
\text { Delivery }\end{array}$ & \% & $\begin{array}{c}\text { Forceps } \\
\text { Delivery }\end{array}$ & \% \\
\hline $\mathbf{1 9 9 3}$ & 1650 & 844 & 51.1 & $384^{*}$ & 23.3 & $421^{*}$ & 25.5 \\
$\mathbf{1 9 9 4}$ & 1747 & 946 & 54.1 & 381 & 21.8 & 419 & 24.0 \\
$\mathbf{1 9 9 5}$ & 1918 & 1038 & 54.1 & 519 & 27.1 & 361 & 18.8 \\
$\mathbf{1 9 9 6}$ & 2018 & 1142 & 56.6 & 613 & 30.4 & 262 & 13.0 \\
$\mathbf{1 9 9 7}$ & 2004 & 1109 & 55.3 & 566 & 28.2 & 329 & 16.4 \\
$\mathbf{1 9 9 8}$ & 2396 & 1280 & 53.4 & $751^{*}$ & 31.3 & $365^{*}$ & 15.2 \\
\hline
\end{tabular}

$*-p<0.01$

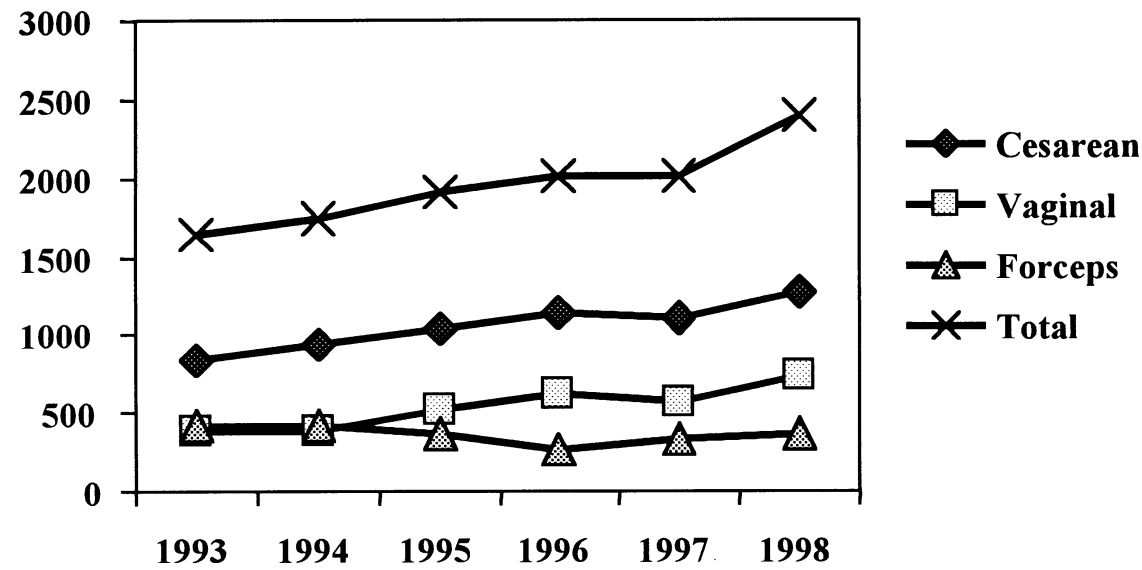

Figure 5 - Number and type of delivery during the study. Note that the proportion of cesarean section increased but not significant $(p>0.05)$. The proportion of vaginal delivery without forceps increased $(\mathrm{p}<0.01)$ and the proportion of forceps delivery decreased significantly $(\mathrm{p}<0.01)$.

Table 7 - Type of delivery according number of fetuses.

\begin{tabular}{cccccccc}
\hline $\begin{array}{c}\text { No. of } \\
\text { fetuses }\end{array}$ & $\begin{array}{c}\text { No. of } \\
\text { pregnancies }\end{array}$ & $\begin{array}{c}\text { Cesarean } \\
\text { Section }\end{array}$ & $\%$ & $\begin{array}{c}\text { Vaginal } \\
\text { Delivery }\end{array}$ & \% & $\begin{array}{c}\text { Forceps } \\
\text { Delivery }\end{array}$ & $\%$ \\
\hline Singleton & $11,165^{*}$ & 5956 & 53.3 & 3170 & 28.4 & 2039 & 18.3 \\
Twins & 258 & 177 & 68.6 & 59 & 22.9 & 22 & 8.5 \\
Triplets & 15 & 15 & 100 & - & - & - & - \\
Quadruplets & 1 & 1 & 100 & - & - & - & - \\
\hline Total & $\mathbf{1 1 , 4 3 9}$ & $\mathbf{6 1 4 9}$ & & $\mathbf{3 2 2 9}$ & & $\mathbf{2 0 6 1}$ &
\end{tabular}

* - In 2 pregnant women with singleton pregnancy, the type of delivery was not specified. In 1 case of uterine rupture, an emergency laparotomy was performed.

ean section among elderly mothers. In the present study, the rate of cesarean section in the elderly group was also significantly higher $(64.8 \%)$ than in the younger patients. However, there were no differences in the birth weights among maternal age groups.

Preterm birth has been, and continues to be one of the most serious problems in obstetrics. It is the most com-
Table 8 - Type of presentation.

\begin{tabular}{lcc}
\hline Fetal Presentation & $\begin{array}{c}\text { No. of } \\
\text { pregnancies }\end{array}$ & $\%$ \\
\hline Cephalic & 10,679 & 91.2 \\
Pelvic & 995 & 8.5 \\
Transverse & 30 & 0.3 \\
\hline
\end{tabular}

Total $\quad 11,704$

* - In 29 pregnant women, the type of Presentation was not specified. 
mon cause of neonatal death and morbidity in surviving infants ${ }^{10}$. Premature labor cannot be prevented effectively ${ }^{11}$. In this study, there was an extremely high incidence of premature labor. This is mainly due to the high incidence of associated maternal and fetal diseases in the patients of this study, which is a characteristic of our institution. However, there was a significant decrease in these figures during the 6 years of the study. On the other hand, the rate of post-term deliveries remained stable during the period of this study. This is because we interrupt gestation at the $42^{\text {nd }}$ week, following our protocol of management of pregnancy. There is still debate as to whether active induction is advisable for post-term pregnancy. Some authors ${ }^{12,13}$ believe that routine induction of labor in postdate pregnancy may reduce perinatal morbidity, while others suggest that there is no difference in the fetal outcome without active induction of the labor ${ }^{14}$.

The frequency of twin births in the present study $(2.4 \%)$ and sex ratio were similar to other studies in the literature $^{15,16}$. The twinning rate was strongly correlated with maternal age; the rate for mothers over 35 years of age was about 2 times higher than for mothers younger than 20 years, as has also been found in other studies ${ }^{17}$.

As seen in another study ${ }^{18}$, the average duration and the average birth weight decreased as the number of fetuses increased. Retarded fetal growth and preterm delivery are both important etiologies of low weight in multifetal gestations. These factors may have contributed to the higher incidence of fetal death in this particular group of pregnancies.

The proportion of cephalic, pelvic, and transverse fetal presentation found in the present report were similar to those found in some other studies $7,8,11,15$.

Fetal macrosomia is a condition that may increase the risk of mechanical and/or dynamic problems for the patient ${ }^{19}$. The incidence of fetal mac- rosomia varies in the literature between $5.6 \%$ and $6.3 \% \%^{20,21}$. In our hospital, the incidence of birth weights of $4000 \mathrm{~g}$ or more was only $3.1 \%$. The incidence of macrosomia in post-term pregnancy is twice as high as that in term delivery.

Although the incidence of both emergency and elective cesarean section is increasing in developed countries $^{22}$, this incidence is much higher in developing countries such as Brazil. In our service, the overall rate of cesarean section was $54.2 \%$. This may be due to the increased rate of co-existing maternal diseases in our department, which is a tertiary referral service, as well as the existence of two or more previous cesarean sections (contraindication of vaginal delivery in our protocol). According to an international study, Brazil has one of the highest rates of cesarean section $(32 \%)$. The United States reported a rate of $19 \%$, while Japan and Czechoslovakia reported rates lower than $10 \%{ }^{23}$.
SCHUPP TR e col. - Levantamento dos partos ocorridos em um Hospital Universitário: um estudo de seis anos. Rev. Hosp. Clín. Fac. Med. S. Paulo 55(4):137-144, 2000.

Com o objetivo de avaliar alguns dados perinatais da Clínica Obstétrica do Departamento de Obstetrícia e Gi- necologia do Hospital das Clínicas da Faculdade de Medicina da Universidade de São Paulo, os autores apresentam um levantamento de todos os partos ocorridos no período entre 1993 e 1998. O número de partos aumentou em $45 \%$ neste período. O número total de óbitos fetais foi de $526(4,48 \%)$ com redução estatisticamente significa- tiva ( $\mathrm{p}<0,05)$ neste período. Entretanto, não houve aumento concomitante da proporção de gestantes que tiveram assistência pré-natal, que poderia explicar esta melhora. A incidência de parto prematuro também apresentou uma queda significante.

Os autores acreditam que o aumento do número de partos foi principal- 
mente devido ao aumento do número de gestantes encaminhadas ao nosso serviço. Entretanto, este atendimento não teria sido possível sem os esforços para aumentar a rotatividade dos recém-nascidos no berçário e a diminuição do tempo de internação da partu- riente.

Apesar deste aumento, houve melhora nos resultados dos partos realizados no serviço, durante o período de estudo. Esta melhora pode ter sido reflexo da utilização, por equipe homogênea, de padronização através de con- duta assistencial uniforme baseada no amadurecimento e aprimoramento técnico-científico dos últimos anos.

DESCRITORES: Gravidez. Assistência Pré-Natal. Hospital Universitário.

\section{REFERENCES}

1. RAMOS JLA - Avaliação do crescimento intra-uterino por medidas antropométricas do recém-nascido. São Paulo, 1983. 180p. Tese (Doutorado). Faculdade de Medicina da Universidade de São Paulo.

2. ZUGAIB M \& BITTAR RE - Protocolos Assistenciais da Clínica Obstétrica da Faculdade de Medicina da USP. Editora Atheneu, São Paulo, 1996.

3. MINISTÉRIO da Saúde - Pesquisa Nacional de Demografia e Saúde, 1996.

4. ASSESSING adolescent pregnancy-Maine, 1980-1996 - MMWR Morb Mortal Wkly Rep, 1998; 47(21):433-438.

5. MINISTÉRIO da Saúde - Sistema de Nascidos Vivos (SINASC), 1995.

6. SECRETARIA de Saúde do Estado de São Paulo - Projeto de Melhoria da Qualidade da Assistência Obstétrica no Estado de São Paulo. Avaliação das Maternidades. São Paulo, 1996.

7. SMIT Y, SCHERJON AS \& TREFFERS PE - Elderly nulliparae in midwifery care in Amsterdam. Midwifery 1997; 13(2):73-77.

8. SIVALINGAM N \& AVALANIC - The elderly primigravida-evaluation of 90 cases. Singapore Med J 1989; 30(5):460-465.

9. ANATE M \& AKEREDOLU O - Pregnancy outcome in elderly primigravidae at University of Ilorin Teaching Hospital, Nigeria. East Afr Med J 1996; 73(8):548-551.
10. GOEPFERT AR \& GOLDENBERG RL - Prediction of prematurity. Curr Opin Obstet Gynecol 1996; 8(6):417-427.

11. CARSON RJ - The problem of prematurity: premature labour. Mod Midwife 1997; 7(10):8-11.

12. ALFIREVIC Z \& WALKINSHAW AS - Management of post-term pregnancy: to induce or not? Br J Hosp Med 1994, 52(5):218221.

13. KAPLAN B, GOLDMAN GA, PELEDY et al. - The outcome of postterm pregnancy. A comparative study. J Perinat Med 1995; 23(3):183-189.

14. HAUTH JC, GOODMAN MT, GILSTRAP LC et al. - Post-term pregnancy. I. Obstet Gynecol 1980; 56(4):467-470.

15. CAMPANA MA \& ROUBICEK MM - Maternal and neonatal variables in twins: an epidemiological approach. Acta Genet Med Gemellol 1996; 45(4):461-469.

16. Kilby MD, Govind A \& O'Brien PM - Outcome of twin pregnancies complicated by a single intrauterine death: a comparison with viable twin pregnancies. Obstet Gynecol 1994; 84(1):107-109.

17. RAZZAQUE A, AHMED K \& WAI L - Twinning rates in a rural area of Bangladesh. Hum Biol 1990; 62(4):505-514.

18. CUNNINGHAM FG, MACDONALD PC, GANT NF et al. - Multifetal Pregnancy. In Williams Obstetrics $19^{\text {th }}$ ed. Appleton \& Lange Eds. p891-918. 
19. RECH F, LOJODICE S, PATELLA A et al. - Fattori predittivi di megalosomia fetale. Minerva Ginecol 1998; 50(6):225-230.

20. DIANI F, VENANZI S, ZANCONATO G et al. - Fetal macrosomia and management of delivery. Clin Exp Obstet Gynecol 1997; 24(4):212-214.

21. RODRIGUEZ-ROJAS RR, CANTU-ESQUIVEL MG, BENAVIDESDE LA GARZA L et al. - Incidencia de macrosomia fetal. Morbilidad materna y fetal. Ginecol Obstet Mex 1996; 64:247-250.
22. READ AW, WADDELL VP, PRENDIVILLE WJ et al. - Trends in caesarean section in Western Australia, 1980-1987. Med J Aust 1990; 153(6):318-323.

23. NOTZON FC, CNATTINGIUS S, BERGSJO P et al. - Cesarean section delivery in the 1980s: international comparison by indication. Am J Obstet Gynecol 1994, 170(2):495-504

Received for publication on the 24.07 .00 